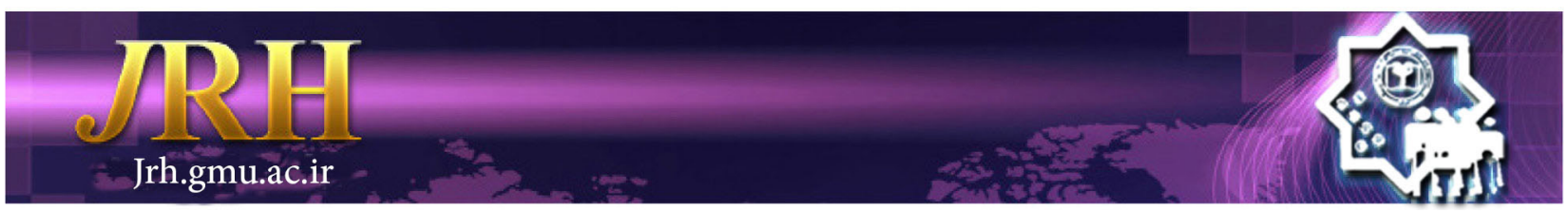

\title{
The role of spirituality in feelings of suffering and quality of life in self-introduced addicts
}

Ali Akbar Pirasteh Motlagh ${ }^{1}, Z_{\text {Zhra Nikmanesh }}^{2}$, Ehsan Liaghat ${ }^{3}$, Mojahed Hematian ${ }^{4}$

\author{
Journal of Research \& Health \\ Social Development \& Health Promotion \\ Research Center \\ Vol. 9, No.2, Mar \& Apr 2019 \\ Pages: 104- 111 \\ DOI: $10.29252 /$ jrh.9.2.104 \\ Original Article
}

1. Correspondence to: Department of Psychology, Faculty of Education Science and Psychology, University of Sistan and Baluchestan, Zahedan, Iran

Email: AAPirasteh88@gmail.com

2. Department of Psychology, Faculty of Education and Psychology, University of Sistan and Baluchestan, Zahedan, Iran

3. Department of Psychology, Faculty of Literature and Humanities, Azad University of Yasuj, Yasuj, Iran

4. Department of Psychology, Faculty of Psychology and Educational Sciences, International University of Imam Khomeini Qazvin, Qazvin, Iran

Received: 15 Sep 2013

Accepted: 5 Sep 2016

How to cite this article: Pirasteh Motlagh AA, Nikmanesh Z, Liaghat E, Hematian M. The role of spirituality in feelings of suffering and quality of life in self-introduced addicts. $J$ Research \& Health2019; 9(2): 104- 111.

\begin{abstract}
Many researches are seeking evidence and ways in which spirituality can improve the feeling of suffering and quality of life in drug abuse addicts. This study was aimed to investigate the role of spirituality in feelings of suffering and quality of life in self-introduced addicts referring to addiction treatment centers. The statistical population consisted all of self-introduced addicts referring to addiction treatment centers in Yasuj city. 120 participants were selected by convenience sampling. Following instruments were used for data collection; spirituality questionnaire, scale of experience and perception of suffering and the world health organization quality of life questionnaire. The results showed that there was a significant negative correlation between spirituality and feelings of suffering. There was a significant positive correlation between spirituality and quality of life. Stepwise regression results showed that the best predictors of spiritual/existential suffering were selfawareness and spiritual activities. Also, the component of selfawareness was the best predictor of physical health, psychological health, environmental health and quality of life and social relations. Therefore, reinforcement of spirituality in addicts and encouraging them to perform the related activities can reduce the feeling of pain among them and improve their quality of lives.
\end{abstract}

Keywords: Addicts, Quality of Life, Spirituality, Suffering

\section{Introduction}

Addiction is a big personal and social problem that in addition to physical and psychological effects on addicts threat and damage the public health in terms of socio-economic, political and cultural aspects [1]. Also, the resulting destructions lead to decline of many cultural and moral values and norms and thus will cause social stagnation in various fields [2]. Potentially maladaptive patterns of drug use lead to severe clinical disorders, anxiety, poor physical and mental performance, loss of personal security and safety, social relationships disorder, loss of job. All of these lead to loss of quality of life and cause great pain in addicts [3]. Moro, Simon, Bard and Racz believed that drug abuse is associated with reduction of quality of life and low levels of spirituality. They argued that this relationship exists in the early stages of drug abuse and drug dependence. But in the final stages of drug 
dependency when the person gets tired of drug use and loses all signs of a healthy life, individual seeks to acquire a healthy life and improve quality of life by resorting to drug treatment and relying on spiritualties [4], as Donovan stated addicts consider treatment as a means to escape from these negative consequences and achieve the lost spirituality and a better life not as a means to quit drugs [3]. On the other hand, the researchers consider the suffering caused by such problems and the consequences of drug addiction in consumers as two kinds of suffering; primary suffering and secondary suffering. The initial suffering is due to the negative emotions, emotional deficiencies and individual needs and also the caused tension and stress. The secondary suffering as unbearable suffering is caused by drug abuse. This suffering is due to the mental and physical effects of drug use, family problems and social relationships disorders related to drug use. And the addicts because of this suffering decide to quit the drug by going to the treatment centres or spiritual selftreatment. Indeed, addicts are in the secondary phase of feeling of suffering $[5,6]$. So that some theorists argue that drug addiction, is a disorder with spiritual dimensions that becomes meaninglessly apparent in life [7].

Many studies support this idea that religion or spirituality has beneficial health outcomes. For example, Ross, Handal, Clark and Vander Wal showed that there is a significant relationship between religion and psychological adjustment [8]. Bell Meisenhelder and Chandler showed that the number of praying, the importance of faith and confidence in religion as coping styles are strongly and positively related to psychological health [9]. The results of Hassani Vajary and Bahrami's study also showed that there is a positive and significant relationship between positive religious coping and general health [10]. Also Poage, Ketzenberger and Olson in their review found that high level of spirituality is associated with life satisfaction [11]. The study of Shademan Masoule, Sheikholeslami, Khodadad and Yazdani revealed that religious beliefs have significant relationship with public health [12].

As you can see in all of these studies, the researchers are seeking for evidence of the ways in which spirituality can improve the psychological health and well-being. Despite all of these, the role of spirituality in feelings of pain and quality of life of drug abusers is often neglected while the importance of these issues can be considered in drug abusers. The relationship of these two variables with each other and with feeling of pain have been rarely considered although few studies have been implicitly and shortly conducted about the spirituality and the life quality of drug abusers. In this regard, the studies of White and Laudet, Laudet, Morgen and White showed that spirituality, religion and the meaning of life with emphasis on the 12-step spiritual program played an impressive and useful role in the quality of life of addicts $[13,14]$.

In addition, Chen in a qualitative study showed that the 12-step spiritual program as a coping way for reduction of the primary and secondary feeling of pain in drug abusers is very efficient [5]. However, the relationship of this variables in other target groups has been investigated and studied systematically, for example; Pirasteh Motlagh and Nikmanesh in studying of the relationship between spirituality with pain feeling and life quality in the patients who suffering Acquired Immune Deficiency Syndrome (AIDS) showed that there is a positive and significant relationship between spirituality and life quality and a negative and significant relationship between spirituality and feeling of suffering [15]. Zeilani and Seymour showed that spiritual understanding of the sense of suffering in patients makes it easier for the patients to cope with their disease and its complications [16]. Also, Kang, Im, Kim, Kim, Song and Sim studied the effectiveness of meaning therapy in the sense of suffering, the meaning of life and spiritual well-being in cancer patients, the results showed a significant difference in feelings of pain and meaning in life between experimental and control groups, however there is no significant 
difference between groups in the spiritual wellbeing [17]. In addition, Pirastehh Motlagh, Nikmanesh and Raghibi found significant negative relationship between spirituality and a sense of physical, psychological and spiritual/ existential suffering [18].

The mentioned theoretical and experimental background can shed light on the path that its explicit aim is the reduction of pain and suffering of the drug abusers and also the improvement of their life quality and psychological health so that these patients can return the normal life and cope with their routine activities. On the other hand, since the moralities training and the related issues are one of the most important and effective factors in the reduction of pain feeling and improvement of psychological health among drug abusers and also regarding the physical, mental, social and family problems which are caused for drug abusers due to their addiction to drugs so it is needed that some activities will be done for reduction of their pains and sufferings. Therefore, in the present study was aimed to investigate the role of spirituality in the feeling of pain and the quality of life in the self-introduced addicts of addiction treatment centres of Yasuj city.

\section{Method}

This research was a analytical study. Spirituality was the predictor variable and feelings of pain and quality of life was criterion variables. The statistical population consisted of all self-introduced addicts referring to addiction treatment centers in Yasuj, south-western of Iran, and the sample included 120 participants who were selected by convenience sampling among all the population.

The data collection instrumentations in this study included Spirituality Questionnaire (SQ), Scale of Experience and Perception of Suffering (SEPS) and the World Health Organization Quality of Life Questionnaire (WHOQOL-BREF).

Spirituality questionnaire (SQ): It was designed by Parsian and Dunning. To measure the importance of spirituality also assesses its different aspects in human life. This tool is a 29-item self-report questionnaire which is Rated on a Likert scale of 1-4 where one represents strongly disagree $=1$, disagree $=2$, agree $=3$, and strongly agree $=4$. The total score and subscale scores of self-awareness (10 questions), importance of spiritual beliefs in life (4 questions), intellectual activity (6 questions) and spiritual needs (9 items) are measured separately. The overall alpha coefficient of the test was reported 0.94 and subscale coefficient of self-awareness is 0.91 , the importance of spiritual beliefs in life 0.91, spiritual activities 0.8 and spiritual needs 0.89 [19]. In the present study reliability of this scale was obtained 0.95 using Cronbach alpha reliability.

Scale of Experience and Perception of Suffering (SEPS): This scale has been designed by Schulz, Monin, Czaja and Lingler [20] which is used to measure the feelings of suffering. Scale of Experience and Perception of Suffering measures three dimensions of suffering as the physical suffering, the psychological suffering and the spiritual suffering. Physical dimension includes 9 items and the subject identifies the answers based on a four-point Likert scale from never $=0$ to always $=3$. Psychological dimension is measured by 15 items. The subject identifies the answer based on the four-point Likert scale from very low $=0$ to very high $=3$. The spiritual dimension is measured by nine items. The subject identifies the answer based on the five-point Likert scale from very low $=0$ to very high $=4$ [20]. The reliability of this test and its dimensions has been approved by Aschalz and colleague in 3 groups of the African-American group (physical 0.63, psychological 0.90 and existential/ spiritual 0.86), whites (physical 0.43 , psychological 0.87 and existential/ spiritual 0.84) and Spanish (physical 0.6, psychological 0.85 and existential/ spiritual 0.83) [20]. The Cronbach's alpha coefficient of physical, psychological and spiritual in research of Pirasteh Motlagh and Nikmanesh were respectively $0.71,0.84$ and 0.81 [15]. In the current study, the reliability of 
this instrumentation using Cronbach alpha coefficient for the subscale of physical suffering was 0.84 , for psychological suffering 0.79 and for spiritual suffering 0.87 .

World Health Organization Quality of Life Questionnaire (WHOQOL-BREF): This questionnaire contains 26 questions and measures four domains of physical health, psychological health, social relations and environmental health with 24 items. Two of the question belong to none of domains, and evaluate the health and quality of life conditions in general. In each domain a score of 4 to 20 for each domain will be separately achieved where, 4 marks the worst and 20 marks the best condition of the considered domain. These points can be converted to a score ranging from 0 to 100 . Reliability of this questioner was obtained through use of Cronbach's alpha and intra-cluster correlation in all domains higher than 0.7 , but in domain of social relationships the value of Cronbach's alpha was 0.55 . On the other hand in $83 \%$ of the cases, the correlation of each question was higher than its original domain correlation of each question with its original domain was higher than other domains [21]. Heydari and Jafari in a study on $100 \mathrm{HIV}$ infected patients and 100 normal individuals in ahvaz city, reliability of the questionnaire using Cronbach's alpha for the total scale were achieved 0.95 [22]. In the present study reliability coefficients of physical health, psychological health, social relationships and environment health were obtained respectively 0.72, 0.86, 0.91, 0.85 using Cronbach's alpha, for the entire questionnaire.

The statistical analysis of data was employed in descriptive and inferential levels. In the descriptive level, frequency, percentage, mean and standard deviation and in inferential level statistics, correlation analysis test and regression analysis were used.

\section{Results}

The descriptive findings related to the participants indicated that $50 \% \quad(n=60)$ were single and $50 \%(n=60)$ were married; educational status of the participants showed that $59.1 \%$ (71 people) have a high school diploma, 36.4\% (44 people) have a BA and $4.5 \%$ (5 people) have a master degree or higher. The employment status of the participants also showed that $18.2 \%(22$ people) are unemployed, $77.3 \%$ (93 people) are self-employed and $4.5 \%$ (5 people) have government jobs. The descriptive findings (mean and standard deviation) of the variables and subscales can be found in Table 1.

Table 1 Mean and standard deviation in measures of spirituality, feelings of suffering, quality of life in addicts

\begin{tabular}{llcc}
\hline Variables & Sub scale & Mean & $\begin{array}{c}\text { Standard } \\
\text { deviation }\end{array}$ \\
\hline \multirow{4}{*}{ Spirituality } & Self-awareness & 29.13 & 5.03 \\
& Importance of spiritual beliefs in life & 12.50 & 1.62 \\
& Spiritual activities & 18.54 & 3.29 \\
& Spiritual needs & 31.72 & 8.54 \\
\hline \multirow{2}{*}{ Feeling of } & Physical suffering & 9 & 4.22 \\
suffering & Psychological suffering & 19.50 & 9.45 \\
& Existential/spiritual suffering & 19.36 & 6.47 \\
\hline \multirow{5}{*}{ Quality of life } & Physical health & 22.09 & 3.84 \\
& Psychological health & 20.72 & 4.60 \\
& Environmental health & 26 & 5.05 \\
& Social relations & 10.04 & 2.29 \\
\hline
\end{tabular}

Before examining the research hypotheses and questions, Kolmogorov-Smirnov test was used as the default test for normality of the data. Kolmogorov-Smirnov test for scores of spirituality variable $(p=0.847)$, feelings of pain variable $(p=0.606)$ and quality of life variable $(p=0.657)$ is not significant. So spirituality, feelings of pain and quality of life variables have normal distribution and parametric analysis can be used for them.

Pearson correlation coefficient was used to review this question that whether the 
relationship between spirituality and its components with feelings of suffering and its dimensions is significant (Table 2).

In general, the results of the relationship between spirituality and feelings of suffering indicate that there is a significant negative relationship between spirituality and feelings of suffering. Also, the relationship between spirituality and the dimensions of suffering feelings indicate that self-awareness component with psychological suffering has significant negative relationship while with spiritual/existential suffering has a significant and positive relationship. Spiritual activities with psychological suffering has significant negative relationship and with the spiritual/existential suffering has a significant and positive relationship. Spiritual needs, only with the physical suffering has negative significant correlation (Table 2).

Also Pearson correlation coefficient was used to test this hypothesis that spirituality and its components have significant relationship with the quality of life and its dimensions (Table 3 ).

Table 2 Correlation between spirituality and its components with feelings of suffering and its dimensions in addicts

\begin{tabular}{lccccc}
\hline Variables & $\begin{array}{c}\text { Self- } \\
\text { awareness }\end{array}$ & $\begin{array}{c}\text { The importance of beliefs in } \\
\text { spiritual life }\end{array}$ & $\begin{array}{c}\text { Spiritual } \\
\text { activities }\end{array}$ & $\begin{array}{c}\text { Spiritual } \\
\text { needs }\end{array}$ & Spirituality \\
\hline Physical suffering & -0.24 & 0.22 & -0.17 & $-0.34^{*}$ & 0.08 \\
Psychological suffering & $-0.52^{*}$ & -0.00 & $-0.38^{*}$ & 0.23 & $-0.46^{* *}$ \\
Existential/spiritual suffering & $0.56^{* *}$ & 0.26 & $0.41^{*}$ & -0.06 & $0.37^{*}$ \\
Overall suffering & $-0.48^{* *}$ & 0.24 & -0.26 & $-0.33^{*}$ & $-0.40^{* *}$ \\
\hline
\end{tabular}

Table 3 Correlation between spirituality and its components with life quality and its dimensions in addicts

\begin{tabular}{|c|c|c|c|c|c|}
\hline Variables & $\begin{array}{c}\text { Self- } \\
\text { awareness }\end{array}$ & $\begin{array}{c}\text { The importance of } \\
\text { spiritual beliefs in life }\end{array}$ & $\begin{array}{r}\text { Spiritual } \\
\text { activities }\end{array}$ & $\begin{array}{l}\text { Spiritual } \\
\text { needs }\end{array}$ & Spirituality \\
\hline Physical health & $0.52 * *$ & $0.38 * *$ & $0.44 * *$ & $0.33^{*}$ & $0.53 * *$ \\
\hline Psychological health & $0.58 * *$ & 0.22 & $0.35^{*}$ & $0.35^{*}$ & $0.53 * *$ \\
\hline Environmental health & $0.57 * *$ & 0.00 & 0.17 & 0.04 & 0.27 \\
\hline Social relations & $0.38 *$ & 0.04 & 0.28 & $0.36^{*}$ & $0.43^{*}$ \\
\hline Quality of life & $0.63 * *$ & 0.19 & $0.36^{*}$ & 0.29 & $0.51 *$ \\
\hline
\end{tabular}

The results of Table 3 show that there is a significant positive relationship between spirituality and quality of life. The relationship between spirituality and quality of life revealed that self-awareness component has significant positive correlation with social health dimensions, psychological health, Environment health and social relations. The components of the importance of spiritual beliefs in life only has positive significant relationship with physical health. Spiritual activities component also has a significant positive relationship with the physical health dimensions and psychological health. There is a significant positive relationship between spiritual needs component and the physical health dimensions, psychological health and social relations (Table 3 ).

The results of stepwise regression to predict the spiritual/ existential suffering results indicate that in the first step, self-awareness component was entered in the regression equation and $0.45 \%$ of the variance was indicated for this dimension and in the second step spiritual activities were entered in the regression equation and $0.57 \%$ of the variance was indicated for spiritual/ existential suffering, and self-awareness $(\mathrm{p}=0.001$, Beta $=0.56)$ and spiritual needs $(p=0.001$, Beta $=0.41$ ), which are the best predictors of the feelings of suffering. Also, the results showed that the components of spirituality were not good predictor for dimensions of physical and psychological suffering (Table 4).

The results of stepwise regression for prediction of the quality of life (physical health, psychological health, environmental health and social relations) through spirituality components showed that only consciousness was entered the regression equation for all 
four dimensions and respectively indicates $0.51 \%, 0.57 \%, 0.540 \% 0.42 \%$ of the variance for these dimensions and it is considered the best predictor of physical health, psychological health, environmental health and social relations (Table 5).

Table 4 Summary of the results of stepwise regression analysis for prediction of the suffering feeling dimensions based on spirituality components

\begin{tabular}{lcccccc}
\hline Criterion variables & Predictor variables & Beta & $\begin{array}{c}\text { Determination } \\
\text { coefficient }\end{array}$ & $\begin{array}{c}\text { Adjusted determination } \\
\text { coefficient }\end{array}$ & $\mathrm{t}$ & sig. \\
\hline $\begin{array}{l}\text { Existential/spiritual } \\
\text { suffering }\end{array}$ & Self- awareness & 0.56 & 0.568 & 0.54 & 6.109 & 0.001 \\
\cline { 2 - 7 } & Spiritual activities & 0.41 & 0.418 & 0.57 & 4.430 & 0.001 \\
\hline
\end{tabular}

Table 5 Summary of the results of stepwise regression analysis for prediction of the quality of life dimensions based on spirituality components

\begin{tabular}{lcccccc}
\hline Criterion variable & $\begin{array}{c}\text { Predictor } \\
\text { variable }\end{array}$ & Beta & $\begin{array}{c}\text { Determination } \\
\text { coefficient }\end{array}$ & $\begin{array}{c}\text { Adjusted determination } \\
\text { coefficient }\end{array}$ & t & sig. \\
\hline Physical health & Self -awareness & 0.52 & 0.526 & 0.51 & 5.272 & 0.001 \\
Psychological health & Self -awareness & 0.58 & 0.585 & 0.57 & 6.518 & 0.001 \\
Environmental health & Self -awareness & 0.57 & 0.578 & 0.54 & 7.434 & 0.001 \\
Social relations & Self -awareness & 0.38 & 0.388 & 0.42 & 4.434 & 0.001 \\
\hline
\end{tabular}

\section{Discussion}

The results of the relationship between spirituality and feelings of suffering showed that there is a significant negative relationship between spirituality and feelings of suffering. In fact, levels of feeling of suffering would be decreased by increasing levels of spirituality. The results of the relationship between spirituality with a sense of suffering showed that selfawareness component has a significant negative relationship with psychological suffering while it has a significant and positive relationship with the spiritual/existential suffering. Spiritual activities have significant positive correlation with spiritual/existential suffering and significant negative correlation with psychological suffering. Spiritual needs have significant negative relationship only with the physical suffering. In other words, these results show that with increasing of the spiritual activities, spiritual consciousness and spiritual needs of the participants, their physical and psychological sufferings will be reduced but their spiritual/ existential suffering will be increased. The results of stepwise regression for prediction of the spiritual/existential suffering showed that in the first step, consciousness component and in the second step spiritual activities were entered into the regression equation, and these two variables were the best positive predictors of spiritual/ existential suffering. Also, results showed that the spirituality components were not good predictors for dimensions of physical and psychological suffering. These results are consistent with the findings of [5,15-18]. These researchers in their studies showed that people often use religious and spiritual compatibility to find the aim and meaning of their lives, and to cope with feeling suffering and the problems caused by sickness. For example, Zeilani and Seymour believed that some patients consider their sickness as a Divine Exam to be tested whether they can tolerate the pain caused by it and face with it or not [16]. Pirasteh Motlagh and et al found that the effect of spirituality mechanism on suffering patients can be in this way that at first religion/spirituality affects the patients through intermediate mechanisms of healthy life style, self-perception, positive beliefs, hope to the life, and the belief to the life improvement and then fear, tension, and depression of the patients will be reduced. They in continuous, stated that the spirituality may have positive significant correlation with existential/spiritual suffering for this reason that the people with high levels of spirituality understand the greatness of God more and because of this would show more extreme reactions to their sins and omissions. They consider their sickness as a result of a big sin they had committed and due to this sin deserve themselves to be punished and so they experience a big existential/spiritual suffering [18]. 
Also, the relationship between spirituality and quality of life in general showed that there is a significant positive relationship between spirituality and quality of life. In fact, high levels of spirituality are associated with better quality of life. The results of the relationship between spirituality and the dimensions of life quality showed a positive significant correlation between spiritual selfawareness component with social health, psychological health, environmental health and social relations. The component of the importance of spiritual beliefs in life only had a significant positive correlation with physical health. The component of spiritual activities had a significant positive correlation only with the physical health and psychological health. There was a significant positive correlation between the components of spiritual needs with physical health, psychological health and social relationships. The results of stepwise regression for prediction of the quality of life through spirituality components showed that for every four dimensions of quality of life only the component of spiritual consciousness was entered into regression equation and was the best predictor of physical health, psychological health, environmental health and social relations. These results are in consistent with the findings of $[13,14]$ and partly with the results of the researches [8-12,15]. The researchers noted in their study that the importance of faith, religiosity and spirituality as useful coping styles is strongly and positively related to public health, satisfaction with life, healthy lifestyle and improved life quality. For example, White and Ludet; and Ludet and colleagues have shown that how religious beliefs can affect all aspects of the patient's life physically, psychologically and socially influence. In their study, patients knew one of the perceived supportive sources as moral support and attention to the supernatural and the divine power $[13,14]$.

One of the research constraints was the implementation of research in the drug abuse addicts community, Therefore, generalization results to other people should be cautious.
Therefore, it is suggested that addiction treatment centers and clinics use spiritualreligious compatibility in their psychological treatment in psychotherapy interventions of drug abuse patients. Also, spiritualreligious training is recommended to cultural, educational, and therapeutic practitioners in order to increase mental-social health, improve quality of life, and reduce the feeling of suffering in drug abuse patients.

\section{Conclusion}

So, regarding the negative relationship between spirituality and feeling of suffering and positive relationship between spirituality and quality of life and as well as the positive role of spirituality in prediction of physical, psychological, and social health, and improved life quality of addicts, strengthen of the spiritual and religious attitudes among addicts and encouraging and orienting them to perform the related activities can reduce the feeling of suffering in them and improve their quality of life. Therefore, religiousspiritual trainings can be hold to enhance the psycho-social health, reduce the suffering and improve the quality of life of addicts by spiritual-cultural practitioners and authorities of the drug addiction treatment centers.

\section{Acknowledgments}

The authors' gratitude is expressed to the department of treatment deputy of Yasuj University of Medical Sciences and Prevention Deputy of Welfare Organization of Kohgiluyeh and Boyer-Ahmad province and also all personnel of Hekmat drug addiction treatment center in Yasuj for their kindly cooperation in this study.

\section{Contribution}

Study design: ZN

Data collection and analysis: EL, MH

Manuscript preparation: AAPM

\section{Conflict of Interest}

"The authors declare that they have no competing interests". 


\section{Funding}

The author (s) received no financial support for the research, authorship and/or publication of this paper.

\section{Reference}

1- Din Mohammadi MR, Amini K, Yazdankhah MR. Social and environmental factors affecting this trendopiate Perspective B drug addicts to accept treatment and follow-up introduction welfare organization of Zanjan. Journal of Zanjan University of Medical Sciences2008; 15(59): 85-94.

2- Farshad H, Shokrollahi MA, Dzhpsnd S, Memar Kermani N. Prevention of addiction (smoking and drugs). Office of health promotion and education department of the ministry of health and medical education cooperation with poor mobilization of Islamic revolution Iranian revolutionary guards. 2010.

3- Donovan D, Mattson ME, Cisler RA, Longabaugh R, Zweben A. Quality of life as an outcome measure in alcoholism treatment research. J Stud Alcohol2005; 15: 119-39.

4- Moro L, Simon K, Bard I, Racz J. Autognosis, life quality, and spirituality in psychedelic drug users. Psychedelic science in the 21st century. San Jose: California. 2010.

5-Chen G. Social support, spiritual program and addiction recovery. Int J Offender Ther Comp Criminol2006; 50(3): 306-23.

6- Du Pont RL, Mc Govern JP. Suffering in addiction: alcoholism and drug dependence. In: Starck PL, McGovern JP, eds. The hidden dimension of illness: human suffering. New York: NLNP; 1992. pp: 155-201. 7- Chapman RJ. Spirituality in the treatment of alcoholism: a world view approach. Counseling and Values 1996; 41(1): 39-50.

8- Ross K, Handal JP, Clark ME, Vander Wal SJ. The relationship between religion and religious coping: religious coping as a moderator between religion and adjustment. J of Religion and Health2009; 48(4): 454-67. 9- Meisenhelder JB, Chandler EN. Spirituality and health outcomes in the elderly. $J$ of Religion and Health2002; 41(3): 243-52.

10- Hassani Vajary K, Bahrami Ehsan H. The role of religious coping and spiritual happiness in explaining psychological health. Journal of Psychology2005; 9(3): 87-73.

11- Poage ED, Ketzenberger KE, Olson J. Spirituality, contentment and stress in recovering alcoholics. Addict Behav2004; 29(9): 1857-62.

12- Shademan Masoule MR, Sheikholeslami F, Khodadad $\mathrm{N}$, Yazdani MA. The role of religious belief in general health of aged the member retirement center university of Gilan medical sciences in rasht city. Holistic Nursing and Midwifery Journal2010; 20(63): 26-22.

13- White W, Laudet A. Spirituality, science and addiction counseling. Counselor Magazine2006; 7(1): 56-9.

14- Laudet AB, Morgen K, White WL. The role of social supports, spirituality, religiousness, life meaning and affiliation with 12-Step fellowships in quality of life satisfaction among individuals in recovery from alcohol and drug problems. Alcohol Treat Q2006; 24(1-2): 33-73.

15- Pirastehh Motlagh AA, Nikmanesh Z. The relationship of spirituality with feeling of suffering and quality of life in AIDS patients. Armaghane Danesh Journal2012; 17 (4): 348-337.

16-Zeilani R, Seymour JE. Muslim women's experiences of suffering in Jordanian intensive care units: a narrative study. Intensive Crit Care Nurs2010; 26(3): 175-84.

17- Kang KA, Im JI, Kim HS, Kim SJ, Song MK, Sim S. The effect of logo therapy on the suffering, finding meaning, and spiritual well-being of adolescents with terminal cancer. Ournal of current directions in psychological science 2009 Apr; 312.

18- Pirastehh Motlagh AA, Nikmanesh Z, Raghibi $M$. The role of spirituality and awareness and attitude toward illness in feeling of suffering AIDS patients. [Thesis]. Public psychology. Sistan \& Baluchestan: University of Sistan \& Baluchestan 2011.

19- Parsian N, Dunning T. Developing and validating a questionnaire to measure spirituality: a psychometric process. Glob J Healh Sci2009; 1(1): 2.

20- Schulz R, Monin JK, Czaja SJ, Lingler JH. Measuring the experience and perception of suffering. Gerontologist2010; 50(6): 774-84.

21- Nejat S, Montazeri A, Holakouee Naini C, Mohammad K, Majd Zade SR. Standardization of the world health organization quality of life questionnaire: translation and psychometric Iranian type. Journal of Hygiene School and Health Research Institute2006; 4(4): 1- 12.

22- Heydari AR, Jafari F. Compare the quality of life, social support and general health of people infected with AIDS virus than normal people of Ahvaz city. Journal of New Findings in Psychology2009;2(7):47-60.

\footnotetext{
Copyright(C) 2016 ASP Ins. This open-access article is published under the terms of the Creative Commons Attribution-NonCommercial 4.0 International License which permits Share (copy and redistribute the material in any medium or format) and Adapt (remix, transform, and build upon the material) under the Attribution-NonCommercial terms.
} 